\title{
VISUAL OUTCOME AFTER CATARACT SURGERY AT THE UNIVERSITY
} COLLEGE HOSPITAL, IBADAN

\author{
O.O. Olawoye ${ }^{1}$, A.O. Ashaye ${ }^{1}$, C.O. Bekibele ${ }^{1}$ and B.G.K. Ajayi ${ }^{2}$
}

${ }^{1}$ Department of Ophthalmology, University College Hospital Ibadan, Nigeria

${ }^{2}$ Ojulowo Specialist Eye Centre, Mokola Ibadan

\section{Correspondence:}

Dr. Olusola O. Olawoye

Department of Ophthalmology,

University College Hospital Ibadan,

Nigeria.

E-mail: solaolawoye@yahoo.com

Tel.: +2348023890063

\begin{abstract}
Aim: The aim of this study was to determine the visual outcome of patients who had cataract surgery in the University College Hospital Ibadan.

Methodology: This is an observational descriptive, longitudinal study of consecutive patients undergoing cataract surgery at the University College Hospital conducted between May and October 2007. A total of 184 patients who presented to the hospital and met the inclusion criteria were recruited into the study. Patients were examined preoperatively, 1st day postoperatively and 8th week postoperatively.

Results: The mean age was 66.5 years; and the male to female ratio was 1.2:1. Preoperatively, 137 patients $(74.5 \%)$ were blind in the operated eye, while 39 patients $(23.6 \%)$ were blind in both eyes at presentation. At $1^{\text {st }}$ day postoperatively, 87 patients $(47.3 \%)$ had pinhole visual acuity of $6 / 6-6 / 18$. Best corrected vision after refraction eight weeks postoperatively showed that 127 patients out of 161 patients $(78.8 \%)$ had good vision while 28 patients $(17.4 \%)$ had borderline vision, and six patients $(3.8 \%)$ had severe visual impairment after refraction. The number of bilaterally blind patients also reduced from $39(23.6 \%)$ to one $(0.6 \%)$. Uncorrected refractive error was the commonest cause of poor vision prior to refraction. Glaucoma was the commonest ocular co-morbidity accounting for poor vision in $9.1 \%$ of patients eight weeks after cataract surgery.

Conclusion: This study demonstrates that good results can be obtained with cataract surgery and intraocular lens implantation in the developing world. More attention should be directed towards ensuring that successful outcomes are indeed being realized by continued monitoring of postoperative visual outcomes and prompt refraction for all patients.
\end{abstract}

Keywords: Cataract, Visual outcome, Cataract surgery

\section{INTRODUCTION}

Cataract is the main cause of avoidable blindness worldwide, with the developing world accounting for three - quarters of this blindness. ${ }^{1}$ The Nigerian national survey of blindness found that cataract was responsible for $50 \%$ of blindness in Nigeria. ${ }^{2}$ In 1997 approximately 10 million cataract operations were performed globally but despite this, cataract blindness is thought to be increasing by 1-2 million/year. ${ }^{3}$ To address this increasing backlog, significant progress is being made in increasing the output of cataract surgical services in many developing countries. ${ }^{4}$ Cataract control programmes have been established at both local and national levels to reduce the backlog of cataract blindness. These programmes are designed to increase the number of cataract operations and it is assumed that each case operated is a case of restored vision.

However it is becoming evident that the outcome of cataract surgery is not always as good as previously assumed, and much more attention needs to be given to this aspect of surgical services. ${ }^{5}$ Recent population based studies in Nepal, ${ }^{6}$ China, ${ }^{7}$ and India, ${ }^{8}$ show that $40-75 \%$ of people who have had cataract surgery have a presenting visual acuity of worse than $6 / 18$ in the operated eye, and $21-53 \%$ have less than $6 / 60$.

The aim of this study was to determine the visual outcome of patients who had cataract surgery in a 
tertiary hospital in South Western Nigeria, and to identify reasons for poor outcome.

\section{METHODOLOGY}

This was an observational, descriptive, longitudinal study of consecutive patients who presented to the Eye clinic, UCH between May and October 2007. The Ophthalmology department of the hospital has a vibrant cataract outreach programme. This outreach programme was set up to increase cataract surgery rates. It has an outreach team which consists of all cadres of eye care workers. The outreach team reaches out to neighbouring communities and states to provide primary eye care services at different designated centres within the community and to refer patients who need more comprehensive eye care to the base hospital $(\mathrm{UCH})$. lt was conducted among adults aged 40 years and above who had visually disabling cataracts.

A total sample of all consecutive, eligible patients who met the inclusion criteria and presented with operable cataract to the hospital within the study period were included. The inclusion criteria were patients who were 40 years and above coming for the first-eye cataract surgery. Patients with traumatic cataracts and those who had cataract surgery for cosmetic reasons were excluded from the study. These patients were excluded because they already had poor prognosis for vision prior to surgery. All surgeries were performed by consultants and senior residents. Most of the surgeries were extracapsular cataract surgery with posterior chamber intraocular lens implantation (ECCE+ PCIOL) and a few were small incision cataract surgery with posterior chamber intraocular lens implantation(SICS+PCIOL). All surgeons were monitored using the cataract surgical outcome monitoring system. In this system, a cataract record form is filled for every patient admitted for cataract surgery. Individual verbal informed consent was obtained from each participant. The study protocol was approved by the Ethical Review Board of the University College Hospital and University of Ibadan. Patients were studied prospectively over an eight week period and data was collected preoperatively, first day and eight weeks postoperatively. Preoperatively, a pretested structured questionnaire was administered to assess the socio-demographic data of each patient and the presenting pre-operative visual acuity unaided and with pinhole in both eyes was recorded. Visual acuity test was done by two trained assistants using the illuminated Snellens chart. Visual outcome was categorized using the World Health Organization ${ }^{9}$ (W.H.O) standard where good vision is $6 / 6$ to $6 / 18$, borderline vision is less than $6 / 18$ to $6 / 60$ and poor vision is less than $6 / 60$. Their postoperative visual acuities (aided and unaided) on the $1^{\text {st }}$ day and eight weeks post-operation were recorded. Refraction was done for patients at eight weeks post-operation. Patients were followed up for eight weeks in this study because of time constraints and to reduce the number of patients lost to follow up (attrition rate).

Data collected was entered in a data base and analyzed using SPSS (Statistical Package for Social Sciences) version 13. Analysis by percentages was used whenever appropriate.

\section{RESULTS}

A total of 184 patients met the inclusion criteria and were enrolled for the study. At eight weeks postoperatively however, only 165 patients were assessed giving an attrition rate of $10.3 \%$ during the study period. The remaining nineteen patients were lost to follow-up.

The ages of the patients ranged from 40 to 100 years with a mean of $65.8 \pm 8.46$ years. There were 100 males

\begin{tabular}{ll}
\hline Age (years) on admission & UCH \\
& $\mathbf{N}=\mathbf{1 8 4}(\mathbf{\%})$ \\
\hline $40-49$ & $12(6.5)$ \\
$50-59$ & $26(14.1)$ \\
$60-69$ & $67(36.4)$ \\
$70-79$ & $51(27.8)$ \\
$>80$ & $28(15.2)$ \\
\hline Total & $\mathbf{1 8 4 ( 1 0 0 \% )}$ \\
\hline Sex & $100(54.3)$ \\
Male & $84(45.7)$ \\
Female & $\mathbf{1 8 4 ( 1 0 0 \% )}$ \\
\hline Total & $29(15.8)$ \\
\hline Occupation & $24(13)$ \\
Farmer & $83(45.1)$ \\
Artisan/labourer & $7(3.8)$ \\
Trader & $25(13.6)$ \\
Driver & $16(8.7)$ \\
Professional & $\mathbf{1 8 4 ( 1 0 0 \% )}$ \\
Others & \\
\hline Total & $88(47.8)$ \\
\hline Educational status & $42(22.8)$ \\
No formal education & $28(15.3)$ \\
Primary education & $26(14.1)$ \\
Secondary education & $\mathbf{1 8 4 ( \mathbf { 1 0 0 } \% )}$ \\
Tertiary & \\
\hline Total & \\
\hline
\end{tabular}

Table 1: Demographic characteristic sof patients (54.3\%) and 84 females (45.7\%). Table 1 presents the demographic characteristics of the patients.

Nine patients $(4.9 \%)$ had coexisting diabetes mellitus while 53 patients $(28.8 \%)$ had coexisting hypertension. Preoperative ocular examination in the operated eye revealed that $137(74.5 \%)$ had presenting visual acuity 
of less than $3 / 60$. Thirty two patients $(17.4 \%)$ had severe visual impairment (VA $<6 / 60-3 / 60)$ while 13 patients $(7.1 \%)$ had borderline vision $(\mathrm{VA}<6 / 18-$ 6/60). Two patients (1.1\%) presented with VA e"6/ 18 in the eye scheduled for surgery. Fig 1 shows the pre and postoperative visual acuity in the operated eye.

Thirty nine patients $(23.6 \%)$ were blind in both eyes at presentation with VA $<3 / 60$. Sixty seven patients $(40.6 \%)$ were visually impaired in the better eye (VA
Visual outcome unaided $1^{\text {st }}$ day postoperatively showed that only 24 patients $(13 \%)$ had uncorrected good vision, 99 patients $(53.8 \%)$ had borderline vision and 61 patients $(33.2 \%)$ had severe visual impairment unaided in the operated eye. With pinhole however, 87 patients (47.3) had good vision, 59 patients $(32.9 \%)$ had borderline vision while 38 patients $(20.6 \%)$ had severe visual impairment. Table 3 shows the aided and unaided visual acuity $1^{\text {st }}$ day postoperatively, and eight weeks postoperatively.

\section{Comparison of pre- and post-operative visual acuity in the operated eye (BCVA)}

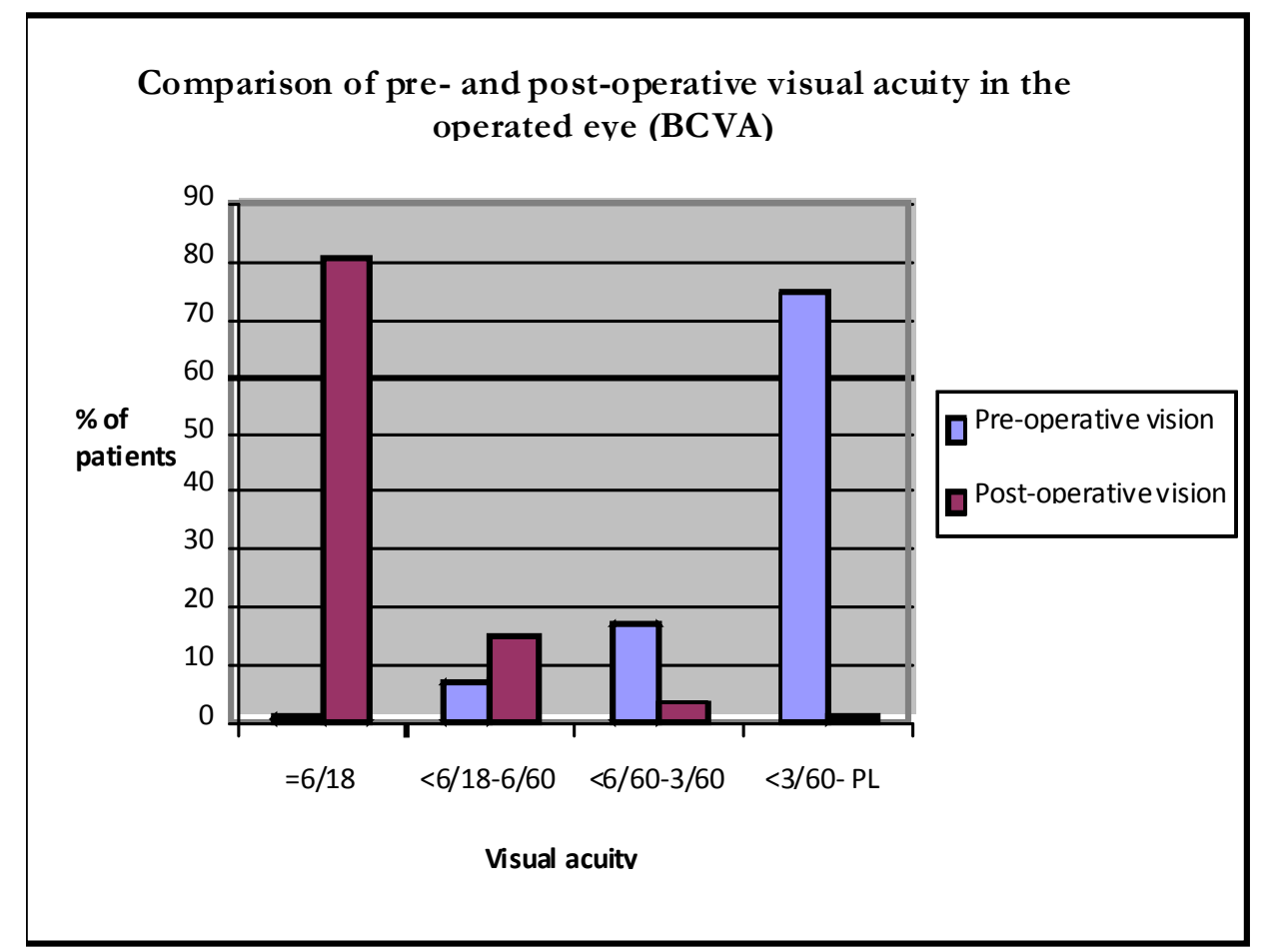

FIG 1: Comparison of Pre- and Post-Operative Visual Acuity (BCVA)

$<6 / 18-3 / 60)$ while 59 patients $(35.8 \%)$ had VA $>6 /$ 18 in the better eye at presentation. Table 2 shows the preoperative and postoperative presenting visual acuity of patient using the better eye. This table shows that cataract surgery reduced the number of patients in the blind category from $23 \%$ to $0.6 \%$ while patients with good vision in the better eye increased from $35.8 \%$ to $85.5 \%$ postoperatively.
At eight weeks postoperatively, the uncorrected visual acuity showed that 64 patients $(38.8 \%)$ had good vision (6/6 -6/18) while 78 patients $(47.3 \%)$ had borderline vision $(<6 / 18-6 / 60)$. Twenty one patients $(12.7 \%)$ had severe visual impairment and two patients $(1.2 \%)$ remained blind despite surgery eight weeks post cataract surgery (Table 3). With pinhole however, 123 (74.6\%) patients out of 165 patients seen at eight weeks postoperatively had good vision, 34 patients $(20.6 \%)$

\begin{tabular}{|c|c|c|c|c|}
\hline Category of vision & \multicolumn{2}{|c|}{$\begin{array}{l}\text { No of patients preoperatively } \\
\text { Unaided Aided (pinhole) }\end{array}$} & \multicolumn{2}{|c|}{$\begin{array}{l}\text { No of patients postoperatively } \\
\text { Unaided Aided (pinhole) }\end{array}$} \\
\hline Bilaterally blind $(<3 / 60-N L P)$ & $42(24.8 \%)$ & $39(23.6 \%)$ & $1(0.6 \%)$ & $1(0.6 \%)$ \\
\hline $\begin{array}{l}\text { Visual impairment in the } \\
\text { better eye }(6 / 18-3 / 60)\end{array}$ & $65(39.4 \%)$ & $67(40.6 \%)$ & $73(44.2 \%)$ & $23(13.9 \%)$ \\
\hline $\begin{array}{l}\text { Good vision in the better eye } \\
(=6 / 18)\end{array}$ & $59(35.8 \%)$ & $59(35.8 \%)$ & $91(55.2 \%)$ & $141(85.5 \%)$ \\
\hline Total & $165(100 \%)$ & $165(100 \%)$ & $165(100 \%)$ & $165(100 \%)$ \\
\hline
\end{tabular}

Table 2: Preoperative and $8^{\text {th }}$ week postoperative presenting visual acuity in the better eye 
had borderline vision while eight (4.8\%) had severe visual impairment. One hundred and sixty one patients had refraction at eight weeks out of which 127 patients (78.8\%) had good vision while 28 patients $(17.4 \%)$ had borderline vision; the remaining six patients $(3.8 \%)$ had severe visual impairment despite refraction. Four patients $(2.4 \%)$ did not have refraction because they defaulted their refraction appointment. They were therefore excluded from the analysis on postoperative refraction. (Table 3).

\begin{tabular}{lll}
\hline $\mathbf{1}^{\text {st }}$ DPO VA & $\begin{array}{l}\text { Unaided } \\
\mathbf{n}(\mathbf{0})\end{array}$ & $\begin{array}{l}\text { Pinhole } \\
\mathbf{n}(\mathbf{\%})\end{array}$ \\
\hline $6 / 6-6 / 18$ & $24(13.0)$ & $87(47.3)$ \\
$<6 / 18-6 / 60$ & $99(53.8)$ & $59(32.1)$ \\
$<6 / 60-3 / 60$ & $30(16.3)$ & $6(3.2)$ \\
$<3 / 60-$ LP & $31(16.9)$ & $32(17.4)$ \\
& $184(100 \%)$ & $184(100 \%)$ \\
Total & \\
\hline \multicolumn{3}{l}{} \\
\hline 8 weeks Post Operation \\
\hline $6 / 6-6 / 18$ & $64(38.8)$ & $123(74.6)$ \\
$<6 / 18-6 / 60$ & $78(47.3)$ & $34(20.6)$ \\
$<6 / 60-3 / 60$ & $21(12.7)$ & $6(3.6)$ \\
$<3 / 60-$ LP & $2(1.2)$ & $2(1.2)$ \\
Total & $165(100 \%)$ & $165(100 \%)$ \\
\hline
\end{tabular}

\begin{tabular}{ll}
\hline \multicolumn{2}{l}{ VA with Refraction } \\
\hline $6 / 6-6 / 18$ & $127(78.8)$ \\
$<6 / 18-6 / 60$ & $28(17.4)$ \\
$<6 / 60-3 / 60$ & $6(3.8)$ \\
\hline Total & $161(100.0 \%)$ \\
\hline Not refracted & $4(2.5 \%)$
\end{tabular}

Table 3: Visual acuity on the $1^{\text {st }}$ day and 8 weeks post cataract surgery

Ocular co- morbidity found in these patients which precluded achieving good vision (6/6 - 6/18) after refraction were glaucoma which was found in 15 patients $(9.1 \%)$, and age related macular degeneration which was found in 4 patients $(2.4 \%)$. Peri-operative complications were cystoid macular oedema in three patients $(1.8 \%)$, severe fibrinous inflammation occurred in two patients $(1.2 \%)$ and endophthalmitis occurred in one patient $(0.6 \%)$. Ten patients had posterior

\begin{tabular}{ll}
\hline $\begin{array}{l}\text { Peri-operative } \\
\text { Complication }\end{array}$ & $\begin{array}{l}\text { UCH (\%) } \\
\mathbf{n}=\mathbf{1 7 0}\end{array}$ \\
\hline Cystoid macular oedema & $3(1.8)$ \\
Fibrinous uveitis & $2(1.2)$ \\
Endophthalmitis & $1(0.6)$ \\
Posterior cap sular rent & $10(6.0)$ \\
No peri-operative complications & $149(90.3)$ \\
Total & $165(100 \%)$ \\
\hline
\end{tabular}

Table 4: Peri-operative complications precluding good vision at 8 weeks capsular rent precluding the insertion of a posterior chamber intraocular lens. Table 4 shows the postoperative complications and ocular co morbidity.

\begin{tabular}{ll}
\hline Glaucoma & $15(9.1)$ \\
Age related macular degeneration & $4(2.4)$ \\
No ocular co- morbidity & $146(88.5)$ \\
Total & $165(100 \%)$ \\
\hline
\end{tabular}

Table 5: Ocular co- morbidity precluding good vision at 8 weeks

\section{DISCUSSION}

Many studies have been done in Nigeria on the visual outcome of patients after cataract surgery ${ }^{10,11,12}$. However many of these studies are retrospective. This is a prospective study and it was done after the commencement of the cataract outreach programme and monitoring of cataract outcome in UCH. Patients were followed up for about eight weeks postoperatively. The age distribution of the patients showed that majority were between the ages of 50 and 79 with a mean age of 65.8 years. This age distribution is in conformity with what is seen in cataract patients in many eye clinics in Nigeria. Nwosu et $a l^{10}$ found a mean age of 66.1 years, Bekibele ${ }^{10}$ found a mean age of 64 years, however Adepoju ${ }^{12}$ et al found a slightly lower mean age of 58.2 years. Similar age range have also been reported in Africa ${ }^{13,14}$ and Asia ${ }^{15}$ There were more males than females in this study. Several studies have found a male preponderance among cataract patients presenting to eye clinics in Nigeria $^{12}$ and Africa. ${ }^{13,14}$ Although women have been shown to have a slightly increased age adjusted risk of cataract, ${ }^{16}$ they do not receive cataract surgery at the same rate as men. ${ }^{17}$

The educational status of the study population is also typical of this age group in developing countries where many of the patients are illiterates and a few are semi literates.

The presenting visual acuity was similar and comparable to those in other African studies. ${ }^{13}$ It showed that most of our patients only seek medical attention when they are blind or almost blind in the two eyes, or at least one eye. This is slightly different from what obtains in developed countries ${ }^{18}$ where patients seek medical attention earlier and therefore present with better visual acuity. In the 1998 European cataract outcome study ${ }^{18}$, only $31.5 \%$ had presenting visual acuity less than $0.1(6 /$ 60).

The results first day postoperatively revealed that there were a larger proportion of patients with corrected (pinhole) good vision compared with what was 
obtained in a large survey in Africa ${ }^{4}$ where good visual outcome at discharge was found among $23 \%$ of patients studied. Adepoju et al ${ }^{2}$ reported that $9 \%$ of patients had good vision within one week of surgery. The comparatively better visual outcome in our patients may be due to the better selection of patients and the regular monitoring of surgeons and cataract outcome. The final visual outcome at eight weeks is better than was reported by Bekibele ${ }^{11}$ at St Mary's hospital in a study carried out between October 1998 and October 1999 where he found good vision in 65.5\%. Agbeja ${ }^{19}$ et al at University College Hospital Ibadan reported good vision (best corrected) in $61 \%$ of patients. It is also better than the best corrected visual acuity $(75.4 \%)$ reported by Nwosu ${ }^{10}$ et al. It is however lower than what was reported by Adepoju $(83.8 \%)^{12}$ where patients were followed up for one year. The patients in this study were followed up for only eight weeks. The values in this study are also lower than those obtained in other studies ${ }^{20}$ where the visual outcome post refraction in patients with intraocular lens was $93 \%$. However in a study carried out on a quarterly basis in Kenya ${ }^{1}$ a range of $77.1 \%-89.4 \%$ was recorded. These differences in the visual outcome are the result of many factors which include the surgeons' skill, presence of intra operative and postoperative complications, and presence of preexisting ocular pathology.

The postoperative visual outcome in this study was worse than the WHO target guideline 9 for visual outcome of cataract surgery where the target proportion of patients with unaided good vision (6/ 6-6/18) should be $80 \%$. In this study, more patients had borderline vision at the end of 8 weeks unaided. This is very different from the $\mathrm{WHO}$ guideline ${ }^{9}$ where the maximum number of patients with unaided borderline vision should not be more than $15 \%$ of the sample population. The most important reason for this finding is uncorrected refractive error as seen by the remarkable improvement in the visual acuity post refraction. This may also be explained by the relatively short follow up period since it has been noted that uveitis tends to last longer postoperatively in Africans because of the heavily pigmented irises. Therefore a longer postoperative period allows for better optimal results. Many of these patients also did not have biometry preoperatively resulting in suboptimal unaided visual outcome at eight weeks postoperatively. A few patients with peri-operative complications also had poor visual outcome at eight weeks post- operation.

Glaucoma was the most common ocular co-morbidity. This is the second most common cause of blindness in Nigeria accounting for $16 \%$ according to the
Nigerian National blindness survey. Improvement in the selection of patients is still necessary in ensuring better optimal visual results.

The importance of monitoring visual outcome cannot be overemphasized as it helps surgeons find ways of improving their surgical skills. It is also important to do preoperative biometry for all patients in order to ensure better vision post-operatively.

In conclusion, this study demonstrates that good results can be obtained after cataract surgery with intraocular lens implantation in the developing world. Increasing cataract surgery with intraocular lens implantation should reduce the number of eyes with poor functional vision after cataract surgery. More attention should be directed towards ensuring that successful outcomes are indeed being realized by continued visual monitoring postoperatively and prompt refraction for all patients.

\section{REFERENCES}

1. Thylefors B, Negrel AD, Pararajasegaram R, et al. Global data on blindness: an update. Bull World Health Organ 1995;73:115-121.

2. Kyari F, Gudlavalleti V.S, Sivsubramaniam S, Gilbert C.E, Abdull M.M, Entekume G, Foster $A$, the Nigeria National Blindness and Visual Impairment Study Group. Prevalence of Blindness and Visual Impairment in Nigeria: The National Blindness and Visual Impairment Survey. Investigative Ophthalmology and Visual Science. 2009; 50:2033-2039.

3. World Health Organization. Global initiative for the elimination of avoidable blindness. Geneva: WHO, 1997; WHO/PBL/97.61

4. Limburg H, Foster A, Gilbert C, et al. Routine Monitoring of Visual Outcome of Cataract Surgery Part 2: Results of 8 Study Centres Br J Ophthalmol 2005;89:50-52.

5. Foster A. Cataract - a global perspective: output, outcome and outlay. Eye 1999;13: 449-53.

6. Pokharel GP,Selvaraj S, et al Visual function and quality of life among cataract operated and unoperated blind population in Nepal. Br J Ophthalmol 1998; 82:606-610.

7. He M, Xu J, et al. Visual acuity and quality of life in patients with cataract in Doumen County, Guangzhou Province, China. 1999; 106: 1609-15.

8. Dandona L, Dandona R, et al. Population based assessment of the outcomes of cataract surgery in an urban population in Southern India. Am J Ophthalmol 1999;127:650-8

9. Ramachandra Pararajasegaram. Importance of Monitoring Cataract Surgical Outcomes. 
Community Eye Health Journal. 2002; 15(44):4950.

10. Nwosu SNN, Onyekwe LO. Intraocular lens implant surgery in Onitsha, Nigeria. NigJ Ophthal Aug 2002; 10(1): 5 - 9.

11. Bekibele CO. Evaluation of the outcome of ECCE surgery with PC IOL at Ago - Iwoye, Osun State, Nigeria. Nig J Ophthal 2001; 9 (1): 32 $-36$

12. Adepoju FG, Owoeye JF, Ademola DS. Assessments of one year follow up of patients with ECCE-PCIOL surgery at University of Ilorin Teaching Hospital, Kwara state, Nigeria. Nig J Ophthal 2004; 12(2): 65 - 69.

13. Yorston D, Gichuhi S, Wood M and Foster A. Does prospective monitoring improve cataract surgery outcomes in Africa? Br J Ophthalmol 2002;86:543-547

14. Karin V, Susan L, et al. Creation and testing of a practical visual function assessment for use in Africa, correlation with visual acuity, contrast sensitivity, and near vision in Malawian adults. $\mathrm{Br}$ J. Ophthalmol 1999; 83:792-795.
15. Nathan GC, Srinivas K, et al. Visual function and postoperative care after cataract surgery in rural China. Archives of Ophthalmology 2007; 11:125127.

16. Lewallen S, Courtright P. Gender and use of cataract surgical services in developing countries. Bull World Health Organ 2002;80(4): 300-303.

17. Anjum KM, Qureshi MB, Khan MA, Jan N, Ali $\mathrm{A}$, Ahmad $\mathrm{K}$ et al. Cataract blindness and visual outcome of cataract surgery in a tribal area in Pakistan. Br J Ophthalmol 2006; 90(2): 135-138.

18. `Mats L, Peter B, et al. Report from the European Cataract Outcome Study group, 1998 European Cataract Outcome Study. 2001; 27 (8): 1176-1184.

19. Agbeja AM. Intraocular lens implantation, the Nigerian experience. Afri J Med Sci 1994; 23: 233 $-237$.

20. Marjan DN, Rudy M. Determinants of Patient satisfaction after Cataract Surgery in 3 Settings. Journal Cataract Refract Surg 2000; 26(9):13791388. 